\title{
Toprak Nem İçeriğinin İzlenmesi ve Tayininde Kullanılan Yöntemler
}

\section{Methods of Soil Moisture Content Monitoring and Determination}

Geliş / Received: 17/12/2020

\author{
Ali Kaan Yetik ${ }^{1 *}$, Mehmetcan Aş1k ${ }^{2}$
}

Revize / Revised: 13/01/2021

Kabul / Accepted: 18/01/2021

\section{$\overline{\mathbf{O Z Z}}$}

Su kaynaklarının etkili kullanımının önemi, dünya nüfusunun katlanarak büyümesi ve iklim değişikliğinin etkileriyle beraber her geçen gün artmaktadır. Büyük bir su tüketicisi olan tarım sektöründe, doğal kaynaklar için kritik öneme sahip olan suyun verimli kullanılması hedefinin küresel anlamda etkileri ve olumlu sonuçları olacaktır. Tarımda suyun verimli kullanılması hem aşırı sulamalardan kaçınmak hem de bitkilere su stresi yaşatmamak için önemlidir. Bu nedenle kullanılacak su miktarının belirlenmesi amacıyla topraktaki mevcut nem miktarının izlenmesi bir zorunluluk haline gelmiştir. Uygulanacak olan sulama programının oluşturulmasıyla, düzenli sulama uygulamaları yapılacak ve minimum sudan maksimum verim elde edilmesi amacının ilk aşaması tamamlanacaktır. Toprak nem içeriğinin belirlenmesinde uygulanan yöntemler doğrudan ve dolaylı olarak ikiye ayrılmaktadır. Gravimetrik yöntem doğrudan toprak nem içeriğini belirlemek için kullanılırken; dolaylı yöntemler, elektromanyetik yansıma zamanının ve frekansının ölçülmesi, elektriksel direnç yöntemi, nötron saçılımı yöntemi ve toprak su potansiyelinin ölçülmesi olarak açıklanmıştır. Dolaylı ölçüm yöntemleri, doğrudan ölçüm yöntemlerine göre toprak nem içeriğinin izlenmesini uygulamada daha pratik hale getirmek için geliştirilmiştir. Ancak bu geliştirmelerin; ekipman fiyatlarının görece yüksek olması, çalışma aralıklarının sınırlı olması, insan sağlığına tehdit oluşturacak unsurlar barındırması ve ekonomik ömürlerinin sınırlı olması gibi farklı sonuçları olmuştur. Bu çalışmada toprak nem içeriğinin belirlenmesinde kullanılan yöntemler hakkında bilgi verilmiş ve sahip oldukları avantaj ve dezavantajlar incelenmiştir.

\section{Anahtar Kelimeler- Gravimektrik Yöntem, TDR, FDR, Nötronmetre, Tansiyometre}

\begin{abstract}
The importance of efficient use of water resources is increasing with the exponential growth of the world population and the effects of climate change. In the agricultural sector, which is a great water consumer, the goal of efficient using of water, which is critical for natural resources, will have global effects and positive results. Efficient use of water in agriculture is important both to avoid excessive irrigation and to not being in water stress for plants. For this reason, it has become a necessity to monitor the amount of moisture in the soil in order to determine the amount of water to be used. With the constitute of the irrigation scheduling to be implemented, regular irrigation applications will be made and the first phase of the aim of obtaining maximum efficiency from minimum water using will be completed. Determination of soil moisture content methods is divided into two as direct and indirect. While gravimetric method is used to directly determine soil moisture content; indirect methods are described as measurement of electromagnetic reflection time and frequency, electrical resistance method,
\end{abstract}

\footnotetext{
1*Sorumlu yazar iletişim: alikaanyetik@ohu.edu.tr (https://orcid.org/0000-0003-1372-8407)

Biyosistem Mühendisliği Bölümü, Niğde Ömer Halisdemir Üniversitesi, Niğde, Türkiye

2İletişim: mehmetcan28a@gmail.com.com (https://orcid.org/0000-0002-1816-747X)

Biyosistem Mühendisliği Bölümü, Bursa Uludağ Üniversitesi, Bursa, Türkiye
} 
neutron probe method and measurement of soil water potential. Indirect measurement methods have been developed to make monitoring soil water content more practical in application than direct measurement methods. But these improvements caused different consequences, such as relatively high equipment prices, limited working intervals, threats to human health, and limited economic life. In this study, information was given about the methods used in determining soil moisture content and their advantages and disadvantages were examined.

\section{Keywords- Gravimetric Method, TDR, FDR, Neutron Probe, Tensiometer}

\section{GíRiş}

Su yenilenebilir bir kaynaktır ancak bulunabilirliği değişken ve sınırlıdır [1]. Günümüzde iklim değişikliğinin de etkisi ile birlikte su kaynakları büyük bir tehdit altındadır. Mevcut su yönetimi uygulamaları, iklim değişikliğinin su kaynaklarına olan tehdidi ile başa çıkacak kadar güçlü olmayabilir. Meydana gelecek düzensiz yağışlar ve ortalamanın altındaki veya üstündeki sıcaklıklar sebebiyle büyük sel ve/veya kuraklık olayları yaşanması beklenebilir. Bu tehditle mücadelenin ilk adımı olarak; iklim değişikliği hakkındaki mevcut bilgilerin su yönetimine adapte edilmesi ve su kaynaklarının daha verimli kullanılması, uzun vadeli etkilerin azaltılmasına yardımcı olacaktır. Aksi takdirde iklim değişikliği etkilerine nüfus artışının da eklenmesiyle birlikte oluşabilecek hasarının telafi edilemez noktaya gelmesi kaçınılmazdır [2].

Dünya üzerindeki mevcut su varlıklarının sektör bazında kullanım verileri incelendiğinde; tarımsal faaliyetlerin sahip olduğu oranın yaklaşık \%70 olduğu görülmektedir. Kalan \%30'luk kısmın ise \%11'i evsel, \%19’u sanayi sektöründeki kullanımlara aittir [3, 4]. 20. Yüzyılın sonlarından itibaren farkındalığı artmaya başlanan su kıtlığı, tarımsal kalkınmayı kısıtlayan en büyük faktör haline gelmiştir [5]. Mevcut suyun \%70'ini kullanan tarım sektöründe kaynakların verimli kullanılması küresel anlamda olumlu sonuçlar doğuracaktır. Tarımda suyun etkili kullanımın en önemli aşamalarından biri bitkinin su ihtiyacının belirlenmesidir. Zira verim ve su ihtiyacı arasındaki ilişki ile optimum sulama yöntemleri, sulama suyu miktarı ve su kaynaklarının önemi yapılan birçok bilimsel çalışmayla ortaya konmuştur [6, 7]. Dolaylı etkileri ve uluslararası anlamda öneminden bahsedilen bitki su ihtiyacının belirlenmesi işleminin ana unsurlarından biri ise topraktaki nem miktarının takip edilmesidir.

Toprak nem içeriğinin kesin ve mutlak bir şekilde tahmin edilmesi, başta sulama programları ve yönetimi, bitkinin su ihtiyacının karşılanması, faydalı gübre uygulamaları, su kaynaklarının verimli kullanması ve birçok teknik çalışma için gereklidir [8]. Zirai yetiştiricilikte tatmin edici sonuçlar elde etmek için bitkilerde su stresini en aza indiren bir sulama programına sahip olmak gerekir. Bunu yaparken aşırı sulamadan kaçınmak da sürecin önemli bir basamağıdır. Yetersiz sulama eğilimi, bitki kökü su alma mekanizmasında strese sebep olacaktır. Bu durum fotosentez faaliyetlerinin yanı sıra hücre genişlemesinde de yavaşlamalara sebebiyet verdiğinden verimde oluşacak kayıplar kaçınılmazdır. Öte yandan aşırı sulama, su kaynaklarının tüketilmesinin dışında toprak için de olumsuz sonuçlar doğurabilir. Gelişen bir bitki, atmosferik su talebini topraktan karşılayabildiği miktarla dengeleyebilmelidir. Toprakta mevcut bulunan su evapotranspirasyon yoluyla tüketilirken, sulama veya yağışla yenilenir ve toprak katmanlarında tutulur. Toprak ve su ilişkileri, bitki büyümesi ve yetiştiricilik üzerindeki etkisinin yanında yüzey akış ve drenajla olan bağlantıları sebebiyle de geçmişten günümüze insanoğlunun ilgisini çekmiştir [9].

Toprak su içeriğinin geleneksel tanımı, topraktan alınan numunenin kurutulmadan önce içerdiği su kütlesinin, $105^{\circ} \mathrm{C}$ 'de kurutulduktan sonraki toplam numune kütlesine oranı şeklindedir [10]. Alternatif olarak ise birim hacim toprakta bulunan suyun hacmi, toprak su içeriğinin bir ölçüsü olarak kullanılabilir. Bu sebeple bitkitoprak-su ilişkileri çalışmalarında genellikle kullanılan su içeriği boyutsuz bir oran veya yüzde olarak görülmektedir. Bu gravimetrik ve hacimsel tanımların eşdeğer olmadığı göz önüne alındığında, belirtilen su içeriğinin iki kütlenin mi yoksa iki hacmin oranı olarak mı belirlendiğini belirtmek oldukça büyük önem taşımaktadır. Nem içeriğinin belirlenmesi yöntemleri temelde, doğrudan ve dolaylı olarak ikiye ayrılmaktadır. Doğrudan yöntemler, kavramın tanımını da içeren toprak numunesindeki su miktarının ölçülmesi ve kurutulduktan sonra orantılanması prensibine dayanırken; dolaylı yöntemler ise toprak su potansiyelinden ve toprak numunesinin barındırdığ 1 suyun bazı kimyasal veya fiziksel özelliklerinin kullanılmasıyla yapılan ölçümlerdir. Bu özellikler arasında dielektrik sabiti, iletkenlik, 1sı kapasitesi, hidrojen miktarı ve manyetik duyarlıliklar gibi kavramlar mevcuttur. Doğrudan yöntemlerin aksine dolaylı yöntemler toprağa daha az zarar verir ve arazide tahribat oluşturmaz. Dolaylı yöntemlerin doğruluğu, kullanılan yöntemin ilkelerine ne kadar sadık kalındığı veya kullanılan cihazın kalibrasyonunun doğruluğuna göre değişebilmektedir [11]. 


\begin{tabular}{|c|c|c|}
\hline & $\begin{array}{l}\text { BŞEÜ Fen Bilimleri Dergisi } \\
8(1), 484-496,2021\end{array}$ & $\begin{array}{r}\text { BSEU Journal of Science } \\
\text { https://doi.org/10.35193/bseufbd.842370 }\end{array}$ \\
\hline 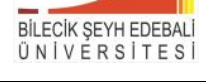 & & 2458-7575 (https://dergipark.org.tr/tr/pub/bseufbd) \\
\hline
\end{tabular}

Teknolojinin ilerlemesiyle birlikte toprak nem içeriğinin belirlenmesi yöntemlerinde de devrim niteliğinde ilerlemeler yaşanmıştır [12]. Gravimetrik yöntem olarak adlandırılan ve "Toprak Nem İçeriğinin İzlenmesi" kavramının tanımını oluşturan doğrudan ölçüm tekniğine ek olarak geliştirilen; nötron saçılımı, dielektrik sabitinin belirlenmesi, elektromanyetik yansıma frekansları, elektriksel direncin ve matrik potansiyelin ölçülmesi gibi dolaylı yöntemler ve cihazlar geliştirilmiştir. Bu derleme çalışmasında toprak nem içeriğinin izlenmesinde kullanılan yöntemler ve ekipmanlar incelenerek ulusal literatüre katkı sağlanması amaçlanmıştır.

\section{DOĞRUDAN YÖNTEMLER}

\section{A. Gravimetrik Yöntem}

Gravimetrik yöntem yardımıyla toprak içerisinde bulunan nem miktarı doğrudan belirlenebilmektedir. Toprak nem içeriğinin belirlemesinde örnekleme burgu yardımıyla önceden belirlenen toprak derinliklerinde yapılmaktadır. Örneklemelerde kullanılan ekipmanlar ve farklı burgu çeşitleri Şekil 1. ve Şekil 2.'de gösterilmiştir. Topraktan örnek alırken oldukça hassas davranılmalı ve belirli ağırlıktaki örneklerin yapısının bozulmamasına dikkat edilmesi gerekmektedir [13]. Bu yöntemde kullanılan alüminyum kaplar yüksek sıcaklıktaki etüvlerde 1sıya maruz kalacağı için; erimeyecek ve önemli bir ağıllık kaybetmeyecek şekilde seçilmektedir. Alınan toprak örnekleri, daraları belirli olan bu kaplara hızlıca ulaştıılıp, herhangi bir nem kaybının meydana gelmesini engellemek yöntemin önemli bir basamağını oluşturmaktadır. Daha sonrasında içerisinde toprak örnekleri bulunan kaplar hassas terazi yardımıyla ağırlıkları belirlenerek not edilmekte ve ardından $105^{\circ} \mathrm{C}^{\prime}$ de 24 saat boyunca bekletilmektedir[14]. Etüvden çıkarılan kapların ağırlıkları hassas terazi yardımıyla yeniden belirlendikten sonra iki tartım işlemi arasındaki fark, toprak örneğindeki mevcut suyun ağılığıını vermektedir. Toprak nem içeriği ise toprak örneğindeki mevcut suyun ağırlığının kuru toprağın ağırlığına oranlanmasıyla bulunmaktadır. Uygulaması açıklanan işlem, Eşitlik 1. ile ifade edilmiştir. Toprak içeriğinde yüksek oranda organik madde var ise $50^{\circ} \mathrm{C}$ 'nin üzerindeki numuneler, organik maddenin buharlaşması nedeniyle ağırlık kaybetme riski taşımaktadırlar. Numune kurutma süreleri ve sıcaklıklarının daha kapsamlı bir tartışması Gardner[15]tarafından verilmiştir. Veriler tipik olarak numune kuru ağırlığına veya numune hacmine bölünerek normalleştirilmektedir. Doğrudan su içeriği ölçümleri, kurutma sırasında kaybedilen su miktarının tartılmasına dayandığından gravimetrik ölçümler olarak adlandırılmaktadırlar.

$$
W_{\mathrm{H}_{2} \mathrm{O}}=\frac{m_{1}-m_{2}}{m_{2}-m_{0}} * 100
$$

Eşitlikte;

$\mathrm{m}_{\mathrm{o}}$ : Boş kabın kapăğ ile birlikte kütlesi, g

$\mathrm{m}_{1}$ : Nemli toprak örneği bulunduran kabın kütlesi, $\mathrm{g}$

$\mathrm{m}_{2}: 105^{\circ} \mathrm{C}$ de kurutulmuş toprak örneğin kapla birlikte kütlesi, $\mathrm{g}$

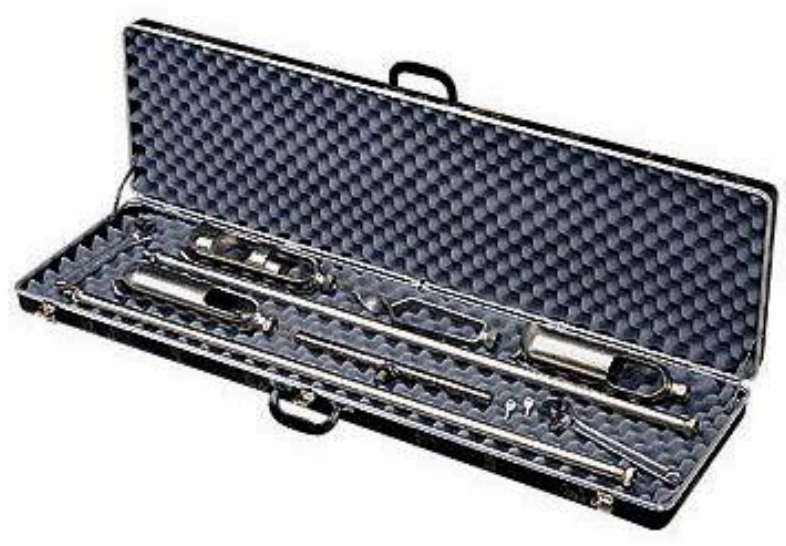

Şekil 1. Toprak örneği alma teçhizatı [16]. 


\begin{tabular}{|c|c|c|}
\hline & $\begin{array}{l}\text { BŞEÜ Fen Bilimleri Dergisi } \\
8(1), 484-496,2021\end{array}$ & $\begin{array}{r}\text { BSEU Journal of Science } \\
\text { https://doi.org/10.35193/bseufbd } 842370\end{array}$ \\
\hline & & 2458-7575 (https://dergipark.org.tr/tr/pub/bseufbd) \\
\hline
\end{tabular}

Gravimetrik yöntemin uygulanmasında her ne kadar örnek alımı esnasında fazla iş gücüne ihtiyaç duyuluyor ve örnekler 24 saat etüvde bekletilmesi gerekiyorsa da ölçümler sonunda elde edilen değerler ile gerçek değerler arasında büyük benzerlikler vardır. Bu durum etkili bir sulama programının oluşturulmasında oldukça önemli rol oynamakta ve daha az su kullanarak daha faydalı bir sulama suyu kullanımı sağlamaktadır. Gravimetrik yönteme ait avantajlar ve dezavantajlar Tablo 1.'de verilmiştir.

Tablo 1. Gravimetrik yöntemin avantajları ve dezavantajları

\begin{tabular}{ll}
\hline \multicolumn{1}{c}{ Avantajlar } & \multicolumn{1}{c}{ Dezavantajlar } \\
\hline $\begin{array}{l}\text { Diğer yöntemlerle karşılaştırıldığında } \\
\text { daha ucuzdur. }\end{array}$ & $\begin{array}{l}\text { Sonuca örnek alındıktan 24 saat } \\
\text { sonar ulaşılabilmektedir. }\end{array}$ \\
Daha doğru sonuç vermektedir. & İs güc üfazladır. \\
Kalibrasyona gerek yoktur. & \\
\hline
\end{tabular}

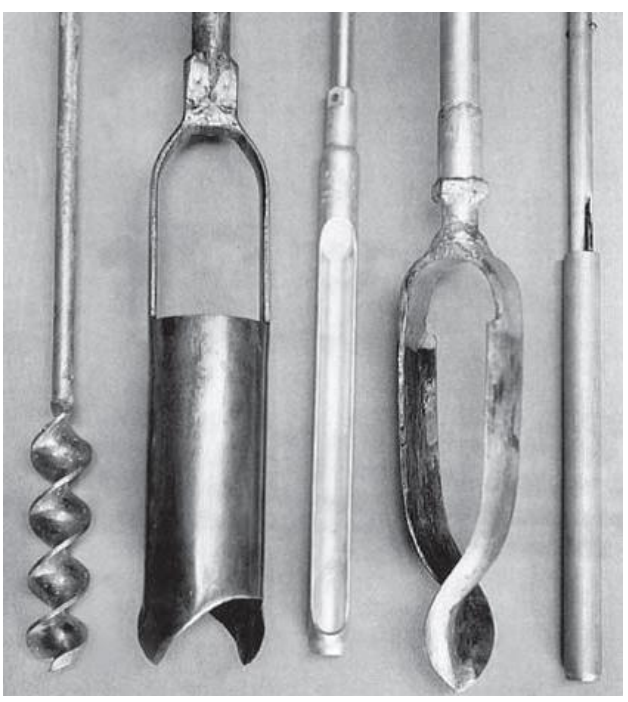

Şekil 2. Toprak burguları ve tüpler [17].

\section{DOLAYLI YÖNTEMLER}

\section{A. Elektromanyetik Yansıma Zamanının Ölçülmesi (TDR)}

TDR yöntemi son zamanlarda kullanılmaya başlanan ve toprağın sahip olduğu dielektrik sabitesinin belirlenmesi yoluyla toprak nem içeriğini hesaplamakta kullanılmaktadır. Bu yüzden toprak nem içeriğinin belirlenmesinde kullanılan bu elektromanyetik yansıma yöntemi diğer yöntemlere göre daha yeni bir yöntemdir [18]. TDR ifadesinin İngilizcedeki açılımı Time Domain Reflectometry'dir ve ifadenin Türkçe anlamı, elektromanyetik yansıma zamanını esas alan ölçümdür.

TDR sistemleri bir radar gibi çalışmaktadır, ölçümler yapılırken problardan yararlanılmaktadır. Genellikle ikili ve üçlü problar kullanılmakta ve yapılan araştırmalarda ikili olan problar üçlü problara göre daha doğru sonuçlar vermektedir. Daha doğru bir okumanın yapılması için prob uzunlukları $30 \mathrm{~cm}$ 'yi aşmamalıdır. Bir uçtan kablo sistemine hızlı bir yükselme süresi darbesi enjekte edilir. Darbe kablodan aşağıya doğru ilerlerken karakteristik empedansta meydana gelen herhangi bir değişiklik olay sinyalinin bir kısmının geri yansıtılmasına sebep olacaktır. Yansıyan darbe bileşenleri, empedansın kablonun karakteristik empedansından büyük veya küçük olmasına bağlı olarak pozitif veya negatif olarak görülmektedir. Koaksiyel kabloya bağlı bir osiloskop yardımı ile elektromanyetik dalganın dönüş süresi ölçülür. TDR darbelerinin yayılma hızı bilindiğinde veya tahmin edilebildiğinde, zaman mesafeye veya konuma dönüştürülmektedir. Şekil 3.’te 3 problu bir TDR aygıtının görüntüsü verilmiştir. 


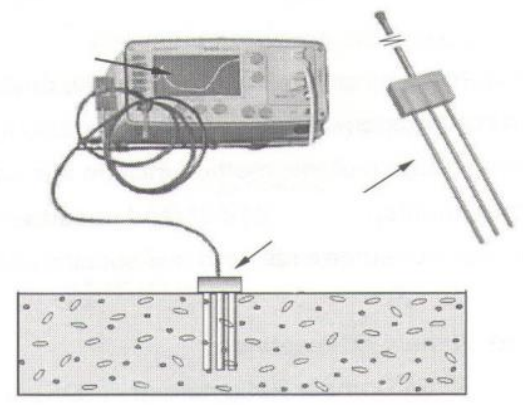

Şekil 3. Probları toprağa dikey olarak yerleştirilmiş 3 problu bir TDR aygıtı [19]

TDR ayrıca dielektrik katsayısını ölçmek için kullanılır, bu da toprak nem içeriğini dolaylı olarak ölçüldüğü anlamına gelir. Toprak içerisinde bulunan su miktarı fazla ise aynı oranda dielektrik kuvvetlerde yüksek değerde olmaktadır [20]. Suyun dielektrik katsayısı diğer toprak bileşenlerinden daha büyük olduğundan, nemli toprağın dielektrik katsayısını ölçerek toprak nem içeriğine ulaşılabilmektedir [21]. TDR yardımıyla toprak içesinde bulunan hacimsel su içeriğinin belirlenmesi Eşitlik 2. ve Eşitlik 3.’te verilmiştir. [22].

$$
\begin{aligned}
& k_{a}=[c * t / 2 L]^{2} \\
& \theta=4.3 \times 10^{-6}\left(k_{a}\right)^{3}-5.5 \times 10^{-4}\left(k_{a}\right)^{2}+2.92 \times 10^{-2} k_{a}-5.3 \times 10^{-2}
\end{aligned}
$$

Eşitliklerde, $\mathrm{k}_{\mathrm{a}}$; toprağın dielektrik sabitini, $\theta$; toprağın hacimsel su içeriğini, c; elektromanyetik dalganın boşluktaki yayılma hızını, t; zamanı, L; probun uzunluğunu göstermektedir.

Toprak tuzluluğu veya yüksek derecede iletken ağır kil içerikleri, yansıyan darbelerin zayıflamasına neden olduğundan TDR'yi etkileyebilir. Başka bir deyişle; TDR, analiz edilebilir bir darbe yansıtıldığı sürece tuzluluğa nispeten duyarsızdır. Yüksek tuzlu koşullara sahip topraklarda, epoksi kaplı prob çubuklarının kullanılması sorunu çözebilmektedir. Ancak bu, hassasiyet kaybı ve kalibrasyonda değişiklikler yapılması anlamına gelmektedir. Gezinme süresine ek olarak, toprakta ilerleyen vuruşun başka bir özelliğinin (yani, boyuttaki değişiklik veya vuruşun zayıflaması) toprak elektrik iletkenliği ile ilişkili olabileceğinin fark edilmesi önemlidir. Buna dayanarak, bazı ticari cihazlar su içeriği ve toprak tuzluluğunu aynı anda ölçme olasılığını içerir. TDR cihazlarına ait avantajlar ve dezavantajlar Tablo 2.'de verilmiştir.

\begin{tabular}{|c|c|}
\hline Avantajlar & Dezavantajlar \\
\hline $\begin{array}{l}\text { Normal tuzluluk düzeylerine karşı duyarsız } \\
\text { olma sebebiyle ölçüm aralığı kısıtlanmıştır. }\end{array}$ & $\begin{array}{l}\text { Tuzlu koşullar altında veya oldukça iletken ağır killi } \\
\text { topraklardan etkilenmektedir. }\end{array}$ \\
\hline Taşıması ve saklaması oldukça kolaydır. & Test ve analiz sonrası için kalifiye operatörler gereklidir. \\
\hline Test sırasında toprağa zarar verilmez. & Pahalı cihazlar kullanılmaktadır. \\
\hline $\begin{array}{l}\text { Sulamada otomasyon sistemlerinin } \\
\text { kurulmasına olanak sağlamaktadır. }\end{array}$ & $\begin{array}{l}\text { Toprakta bulunan tuz içeriği dielektrik sabitesini } \\
\text { değiștirebilir. }\end{array}$ \\
\hline \multicolumn{2}{|l|}{ Toprağa özgü kalibrasyona ihtiyaç yoktur. } \\
\hline \multicolumn{2}{|l|}{ Bakım ve onarım maliyetleri düşüktür. } \\
\hline Doğruluk payları oldukça yüksektir. & \\
\hline
\end{tabular}

Tablo 2. TDR cihazlarının avantajları ve dezavantajları

\section{B. Elektromanyetik Yansıma Frekansının Ölçülmesi (FDR)}

TDR'largigahertz aralığında mikrodalga frekanslarını kullanırken, FDR sensörleridielektrik sabitini tek bir mikrodalga megahertz frekansında ölçmektedir. Mikrodalga dielektrik prob, belirli bir frekansta genliği ve fazı ölçmek için açık uçlu bir koaksiyel kablo ve prob ucunda tek bir reflektometre kullanır. Toprak ölçümleri hava ile ilgilidir ve tipik olarak dielektrik bloklar ve / veya bilinen dielektrik özelliklere sahip sıvılarla kalibre edilir. Kalibrasyon için sıvı kullanmanın avantajı, prob ucu ile malzeme arasında mükemmel bir elektriksel temasın sürdürülebilmesini sağlamasıdır [23]. FDR ve TDR toprak nemini ölçen sensörlerin çalışma prensipleri birbirine 


\begin{tabular}{|c|c|c|}
\hline & $\begin{array}{l}\text { BŞEÜ Fen Bilimleri Dergisi } \\
8(1), 484-496,2021\end{array}$ & $\begin{array}{r}\text { BSEU Journal of Science } \\
\text { https://doi.org/10.35193/bseufbd.842370 }\end{array}$ \\
\hline 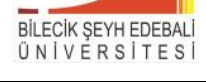 & & 2458-7575 (https://dergipark.org.tr/tr/pub/bseufbd) \\
\hline
\end{tabular}

çok benzemektedir. Ancak FDR sensörlerde elektromanyetik dalgaların frekansları ölçülürken TDR sensörlerde bu dalgaların iletim süreleri ölçülmektedir. İki tip FDR sensör bulunmaktadır. Bunlar; birbirine paralel iki uç ve dairesel metal yüzüğe sahip tiplerdir [24]. Şekil 4.'te kullanılan çeşitli FDR aygıtları verilmiştir.

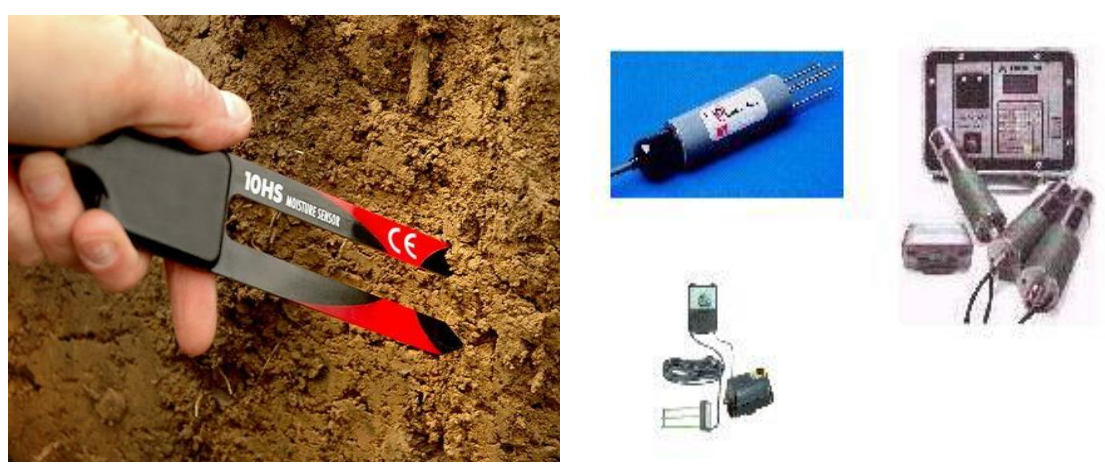

Şekil 4. Çeşitli FDR aygıtları [24] [25].

Problar genellikle toprağa yerleştirilen iki veya daha fazla elektrottan (yani, bir silindirin etrafındaki plakalar, çubuklar veya metal halkalar) oluşur. Halka konfigürasyonunda, prob sahada kurulu bir erişim tüpüne yerleştirilir. Böylece, bir elektrik alanı uygulandığında, elektrotların etrafındaki (veya tüpün etrafındaki) toprak, salınım devresini tamamlayan kapasitörün dielektriğini oluşturur. Bir erişim tüpünün kullanılması, birden fazla sensörün farklı derinliklerde ölçüm almasına olanak tanımaktadır.

Tek, kü̧̈ük bir sonda ucu kullanıldığından, yalnızca küçük bir toprak hacmi değerlendirilir ve bu nedenle toprak tipi oldukça kritiktir. Sonuç olarak, bu yöntem laboratuvar veya nokta ölçümleri için mükemmeldir, ancak bir alan ölçeğinde kullanıldığında muhtemelen uzamsal değişkenlik problemlerine maruz kalacaktır [13]. Bu cihazların çalışma frekansı genellikle 100 MHz'in altında olduğu için toprağa özgü bir kalibrasyon önerilmektedir. $\mathrm{Bu}$ düşük frekanslarda toprak minerallerinin yığın geçirgenliği değişebilir ve sıcaklık, tuzluluk, yoğunluk ve kil içeriğinden daha fazla etkilenir. Düşük frekansta çalıştıklarından dolayı TDR yönteminde tespit edilemeyen toprakta bulanan bağlı su miktarı da ölçülebilmektedir. Düşük frekanslı standart devrelerin kullanılması nedeniyle bazı cihazlar TDR'ye kıyasla nispeten ucuzdur. Ayrıca geleneksel kaydedicilere bağlanabilmektedir. Bunların aksine FDR sensörlerin algılama alanları küçük olması ve güvenilir ölçümler için sensör ile toprak arasında iyi bir temas olması son derece önemlidir bu yüzden hava boşluklarının oluşmasını önlemek için dikkatli bir kurulum yapılması gerekmektedir. FDR yöntemlerinde kalibrasyon işleminin yapılmasına önem verilmelidir [26]. FDR cihazlarına ait avantajlar ve dezavantajlar Tablo 3.'te verilmiştir.

Tablo 3. FDR cihazlarının avantajları ve dezavantajları

\begin{tabular}{ll}
\hline \multicolumn{1}{c}{ Avantajlar } & \multicolumn{1}{c}{ Dezavantajlar } \\
\hline Doğruluk payları oldukça yüksektir. & Toprağa özgü kalibrasyona ihtiyaç duymaktadır. \\
$\begin{array}{l}\text { Geleneksel kaydedicilere bağlanarak (DC çıkış } \\
\text { sinyali) okuma ve depolama yapıllabilir. }\end{array}$ & Sıcaklık, yığın yoğunluğu, kil içeriği ve hava boşluklarına karşı \\
TDR cihazlara göre nispeten ucuzdur. & Ölçüm alanları küçüktür. \\
$\begin{array}{l}\text { Yüksek tuzluluk düzeylerinde okumalar } \\
\text { yapabilir. }\end{array}$ & \\
\hline
\end{tabular}

\section{Elektriksel Direnç Yöntemi (Alçı-Jips Bloklart)}

Yapılan çalışmalarda ilk zamanlar toprak sıcaklığı ve tuz içeriğinde meydana gelen değişiklerden dolayı elektriksel iletkenlik yoluyla toprağın sahip olduğu su içreğinin ölçülmesi başarısızlıkla sonuçlanmıştır. Ancak daha sonraki zamanlarda bu yöntemde alçı bloklar kullanılmaya başlanmış ve bundan neredeyse 50 yıl önce Bouyoucus ve ark., hem fiberglas hem de naylon üniteler kullanarak toprağın su ile doygun durumundan solma noktasına kadar kullanılabileceğini saptamalarılya gerçeklemiş̧ir [27].

Elektrik direnci blok sistemi, toprak nem içeriğini ölçmek için küçük alçı blokları ve taşınabilir bir direnç ölçer kullanır. Bazen alçı bloklar olarak adlandırılan elektriksel direnç blokları, ucuz ve basit bir toprak nemi ölçüm aracıdır. Alçı bloklar, bir çift paslanmaz çelik tel veya tel ızgara etrafına alçı dökülerek yapılmaktadır. Bu teller, 


\begin{tabular}{|c|c|c|}
\hline & $\begin{array}{l}\text { BŞEÜ Fen Bilimleri Dergisi } \\
8(1), 484-496,2021\end{array}$ & $\begin{array}{r}\text { BSEU Journal of Science } \\
\text { https://doi.org/10.35193/bseufbd.842370 }\end{array}$ \\
\hline 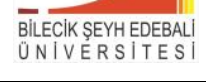 & & 2458-7575 (https://dergipark.org.tr/tr/pub/bseufbd) \\
\hline
\end{tabular}

sayaca takılan elektrot tellerine bağlıdır ve bloklar toprakla temas edecek şekilde yerleştirildiğinde, alçıtaşının nem içeriği toprağın nem içeriğine eşit olma eğilimindedir. Alçıdaki tellerin elektrik direnci nem içeriğine göre değiştiğinden, metre ile elektrik direnci ölçümü toprak nem içeriğinin iyi bir göstergesidir. Toprak ne kadar kuru olursa elektrik direnci o kadar büyük olmaktadır [28]. Bazı sayaçlar, düşük bir gösterge okuması düşük toprak nemini ve yüksek gösterge okuması yüksek toprak nemini gösterecek şekilde inşa edilmiştir. Genel olarak, alçı blokları toprağa, bitkinin köklenme bölgesine yerleştirilir ve büyüme boyunca toprakta kalır. Elektrik direnç blokları, kök büyümesi ve gelişimi sırasında bir nem kontrolü bölgesi sağlamak için toprağın birkaç derinliğine gruplar halinde yerleştirilir [29]. Şekil 5.’te 3 Alçı blok cihazı ve alçı bloklarının araziye yerleştirme biçimi verilmiştir.

Yüksek asitli veya çok tuzlu topraklarda sorunlar meydana gelebilir. Ölçerler taşınabilirdir ve bir veya daha fazla alan boyunca çok sayıda bloğun okunmasında kullanılmak üzere tasarlanmıştır. Özel olarak tasarlanmış sayaçlar analog veya dijital olabilir. Sayaç üzerindeki okumalar, toprak nem içeriği ile ilgili okumaları verecek şekilde kalibre edilmiştir [30].

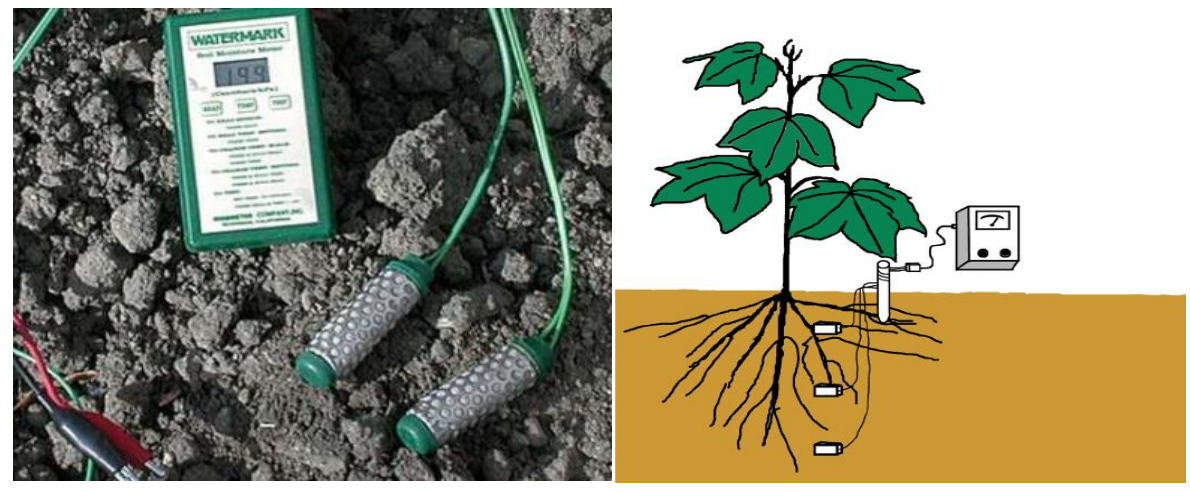

Şekil 5. Alçı blok cihazı ve alçı bloklarının araziye yerleştirme biçimi [28] [31]

Direnç blok yöntemleri çoğu toprak için uygundur ve okumalar sulama yönetimiyle ilgili toprak nem aralıklarının çoğunu kapsar. Böylece toprak nem okumaları sayesinde sulamaların zamanlaması için kullanışlıdırlar, ancak gerekli sulama suyu miktarı hakkında bilgi sağlamazlar. Bloklar bir sahaya kalıcı olarak monte edilir fakat zamanla bozulma eğilimindedir ve bunları yalnızca bir sezon kullanmak ölçümlerin sağlı̆̆ açısından daha doğru olacaktır. Alçı-Jips Bloklarına ait avantajlar ve dezavantajlar Tablo 4.'te verilmiştir.

Tablo 4. Alçı-Jips Bloklarına ait avantajları ve dezavantajları

\begin{tabular}{ll}
\hline \multicolumn{1}{c}{ Avantajlar } & \multicolumn{1}{c}{ Dezavantajlar } \\
\hline Bakım gerektirmez. & Üst üste yapılan ölçümlere elverişli değildir. \\
6 dS/m'ye kadar tamponlanmış tuzluluk etkileri mevcuttur. & Toprak çok susuz kalırsa, çıkarılıp tekrar kurulması gerekmektedir. \\
Basit ve ucuzdur. & Ölçüm hızı yavaştır. \\
Sulama zamanı planlanmasında kullanılabilmektedir. & Kumlu topraklarda güvenilir sonuçlar vermemektedir. \\
\hline
\end{tabular}

\section{Nötron Saçılımı Yöntemi (Nötronmetreler)}

Toprak nem içeriğinin belirlenmesinde nötron atomlarının yayılmalarından faydalanılması 1950'li yılların başlarından itibaren aktif olarak kullanılmaktadır [8]. Tekniğin ana prensibi nötron kaynağına sahip bir probun toprak yüzeyine yerleştirilip kablo aracılığıyla ölçüm yapılacak toprak derinliğine ulaştırılması ve nötron saçılımının ölçülmesine dayanır. Su; topraktaki ana hidrojen kaynağı olduğundan, ölçümün yapıldığı tüp ve radyoaktif kaynak çevresinde oluşan yavaşlamış nötronların yoğunluğu ile toprak nem içeriği takibi mümkün olmaktadır. Nötron atomlarının dağılım (akış) hızı hidrojen atomlarının yoğunluğuyla doğru orantılıdır [32]. Yöntemin uygulanmasında nötronmetre isimli cihaz kullanılmaktadır (Şekil 6.). Nötronmetre, toprak yapısına herhangi bir zarar vermeden tekerrürlü ölçümler yapabilmesi ve çok hızlı sonuç vermesi gibi özellikleriyle ön plana çıkmış bir cihazdır. Teknolojinin gelişmesiyle beraber cihaz ilk kullanıldığı yıllara kıyasla oldukça gelişmiş durumdadır. Bu gelişim cihazın araziye götürülmesinde sağlanan kolaylıklardan, veri aktarımına; kalibrasyon 


\begin{tabular}{|c|c|c|}
\hline & $\begin{array}{l}\text { BŞEÜ Fen Bilimleri Dergisi } \\
8(1), 484-496,2021\end{array}$ & $\begin{array}{r}\text { BSEU Journal of Science } \\
\text { https://doi.org/10.35193/bseufbd } 842370\end{array}$ \\
\hline & & 2458-7575 (https://dergipark.org.tr/tr/pub/bseufbd) \\
\hline
\end{tabular}

kolaylığından kullanıcının sağlığına kadar farklı alanlarda sağlanmıştır. Nötronmetre ile yapılmış birçok araştırma literatürde mevcut bulunmakla beraber, toprak nem içeriğinin izlenmesinde güvenilir bir yöntem olduğu birçok araştırmacı tarafından kabul edilmiştir [33].

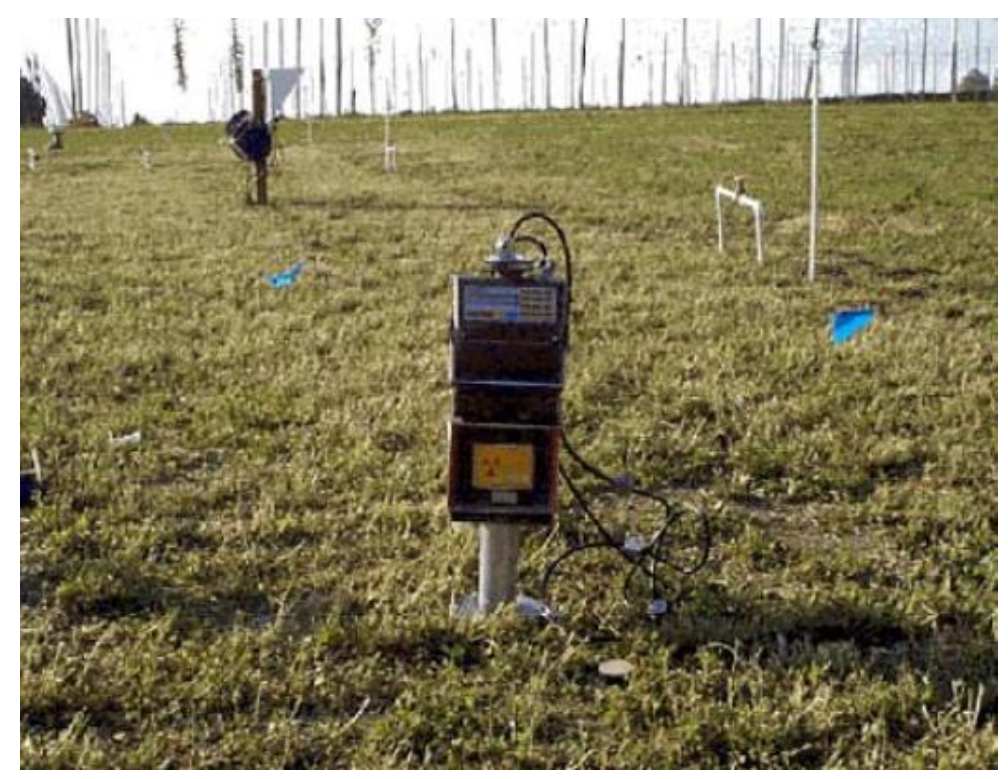

Şekil 6. Nötronmetre cihazı [34]

Nötronmetrelerin farklı model ve versiyonları bulunmasına rağmen tüm cihazlar temelde; hızlı nötronlar yayan bir radyoaktif kaynak, yavaşlayan nötronları sayan bir elektronik sayaç ve bu ikisini birbirine bağlayan bir kablodan oluşur [35]. Ölçümler, toprağa bir alüminyum tüpün çakılarak yerleştirilmesiyle mümkün olmaktadır (Şekil 7.). Tüpün çakılmasında toprağı bozulmalara uğratmamak ve toprakta açılan alanda yerleştirme işleminin tamamlanmasından sonra oluşan boşlukların daha küçük toprak taneleri ile tamamen doldurulması, tüp ile toprak arasında boşluk kalmaması oldukça önemlidir. Nötronmetrelerdeki radyoaktif kaynak genellikle Amerikyum241/Berilyum (Am/Be) karışımı bir maddeden oluşur. Amerikyum-241/Berilyum nötron saçan bir kaynaktır ve ziraat dışında; petrol mühendisliği ve endüstri gibi sektörlerde kullanılır [36]. Bu radyoaktif kaynağa sahip nötron prob çakılan tüplerin içinden ölçülmek istenen derinliğe kadar sarkıtılır. Cihaz ile nötron kaynağını bağlayan kablo üzerindeki kilit sistemi ile farklı derinliklerde ölçüm yapmak mümkündür. Probun ölçüm alanı 1slak toprakta yaklaşık $150 \mathrm{~mm}$, kuru toprakta ise yaklaşık $500 \mathrm{~mm}$ çapında dairesel bir kürenin alanı kadardır [37]. İstenilen derinliğe gelindiğinde cihaz çalıştırılır ve nötron saçılımı başlatılır. Nötron atomları ile aynı kütleye sahip $H+$ iyonundaki protonlar çarpışırlar ve yavaşlama başlar. Yavaşlayan nötron sayıları cihaz içindeki sayaçla ölçülür ve daha önceden hazırlanmış kalibrasyon eğrisinde karşılığı olan toprak su içeriği doğrudan elde edilir [34, 38]. Kalibrasyon eğrilerinin ölçülen bölgeye özel olarak hazırlanması ölçümün doğruluğunu arttıracaktır. Cihazın kalibrasyonu ile ilgili detaylı bilgi Hauser[39] tarafından verilmiştir. 


\begin{tabular}{|c|c|c|}
\hline & $\begin{array}{l}\text { BŞEÜ Fen Bilimleri Dergisi } \\
8(1), 484-496,2021\end{array}$ & $\begin{array}{r}\text { BSEU Journal of Science } \\
\text { https://doi.org/10.35193/bseufbd.842370 }\end{array}$ \\
\hline $\begin{array}{l}\text { BLLECEIS SEYH EDEBALI } \\
\text { ONIVERSITES }\end{array}$ & & 2458-7575 (https://dergipark.org.tr/tr/pub/bseufbd) \\
\hline
\end{tabular}

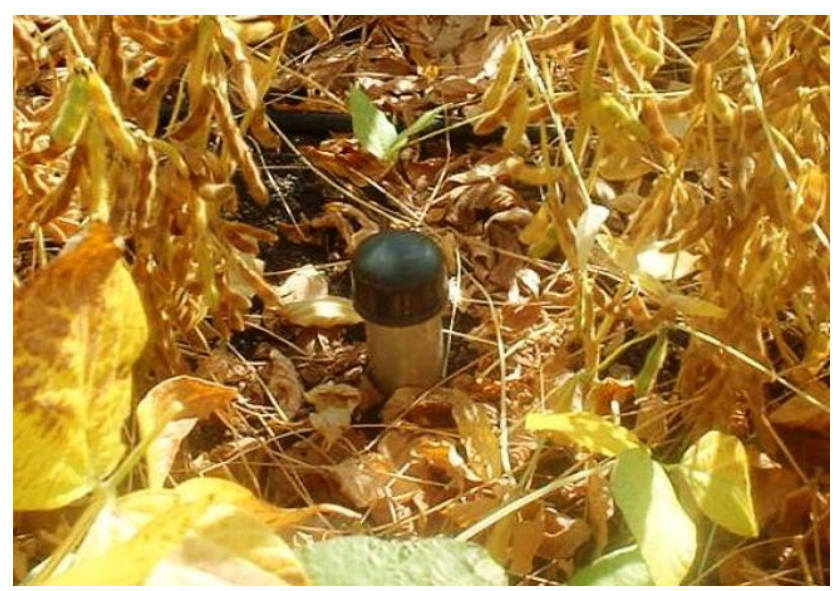

Şekil 7. Nötronmetre ölçümlerinin gerçekleştiği alüminyum tüp [40].

Nötronmetre cihazı ile yapılan çalışmalarda toprak yüzeyine yakın derinliklerdeki ölçümlerde sapmalar olacaktır. Sapmaların sebebi saçılan nötronların atmosfere dağılması ve derinliğin fazla olmamasından kaynaklı toprak temasının azalmasıdır [9]. Bu durum kullanıcının aldığı radyasyon dozunu da artırmaktadır. Nötronmetre çalışma prensibi sebebiyle radyoaktif bir kaynak barındırdığı için kullanıcılarının belirli eğitimler ve bu eğitimler sonucunda da kullanım lisansları almaları gerekmektedir. Türkiye'de bu eğitimler ve lisans Türk Atom Enerji Kurumu (TAEK) tarafından verilmektedir. Nötronmetre kullanıcılarının; cihazın araziye taşınmasından başlayarak ölçümlerin tamamlanmasına ve geri götürülmesine kadar olan süreçte TAEK tarafindan her kullanıcı için özel numaralandırılmış ve kendilerine ulaştırılmış dozimetrelerini (radyasyon ölçer) yanlarında taşıması gerekmektedir. Bu dozimetreler belirli aralıklarla TAEK tarafindan incelenip kullanıcıların maruz kaldıkları radyoaktif madde miktarları takip edilmektedir [41]. Cihazın avantajları ve dezavantajları Tablo 5.'te verilmiştir.

Tablo 5. Nötronmetrelerin avantajları ve dezavantajları

\begin{tabular}{ll}
\hline \multicolumn{1}{c}{ Avantajlar } & \multicolumn{1}{c}{ Dezavantajlar } \\
\hline Ölçümler güvenilir ve hızlıdır. & Toprağa özgü kalibrasyon gerektirir. \\
$\begin{array}{l}\text { Aynı cihazla farklı noktalarda çok sayıda ölçümm } \\
\text { yapılabilir. }\end{array}$ & $\begin{array}{l}\text { Radyoaktif madde ile çalıştığından insan sağlığı } \\
\text { açısından güvenlik tehlikesi bulunur. }\end{array}$ \\
$\begin{array}{l}\text { Tuzluluktan etkilenmez. } \\
\text { Farklı olduğundan taşıması zordur. }\end{array}$ \\
\end{tabular}

\section{E. Toprak Su Potansiyelinin Ölçülmesi (Tansiyometreler)}

Toprak su potansiyelinin ölçümü için tansiyometrenin icadının 1920'nin başlarında WillardGardner tarafından yapıldığı kabul edilir. Saha uygulamalarında ise yapılan ilk sağlam tasarım ve elde edilen başarılı sonuçlar Lorenzo A. Richards'a aittir [42]. Yöntemle topraktaki nem miktarına su matrik potansiyeli ölçerek ulaşılmaktadır. Su matrik potansiyeli; ozmotik basınç, gaz basıncı, yerçekimi kuvveti, toprakta sıkışmış havanın basıncı gibi topraktaki tüm yük bileşenlerinden ve suyun toprak içindeki hareketleri için ana itici güçlerden bir tanesidir [34]. Matrik potansiyelin ölçümünden elde edilen negatif basınç değerleri ve toprak su içeriği arasındaki toprak su karakteristik eğrisine ait denklemle beraber tansiyometrelerin en önemli avantajlarından biri elde edilmektedir. Hem matrik basıncı ölçebilmesi ve hem de oluşturulan toprak su karakteristik eğrisini kullanılarak toprak su içeriği hakkında bilgi edinilebilmektedir [43]. Hem geçmişte hem günümüzde birçok farklı boyut ve modellerde tansiyometre bulunmaktadır. 1920'li yıllardan sonra kullanılmaya başlandığı yıllardaki durumu ve farklı kullanım tipleri Richards[44]tarafından incelenmiş olup, günümüzde kullanılan yaygın türlerinde üç farklı okuma tipi vardır. Bunlar su manometreliler, cıvalı manometreliler ve vakum kadranlı tansiyometrelerdir [45]. En çok kullanılan vakum kadranlı manometreye sahip bir tansiyometrenin görüntüsü Şekil 8.'deki gibidir. Tansiyometreler içi su dolu bir gövde, seramik uç ve bir manometreden oluşmaktadır. Gövdenin en alt kısmında bulunan seramik uç, çok küçük gözeneklerden oluşmaktadır ve bu gözeneklerden giren hava basıncının maksimum 
değeri -0.8 bar olabilmektedir [46].Bu düşük hava basıncından sağlanan en büyük fayda suyun uçlara hareketinin kolaylaşması ve bu harekete ters kuvvet oluşturabilecek bir hava girişinin engellenmesidir.

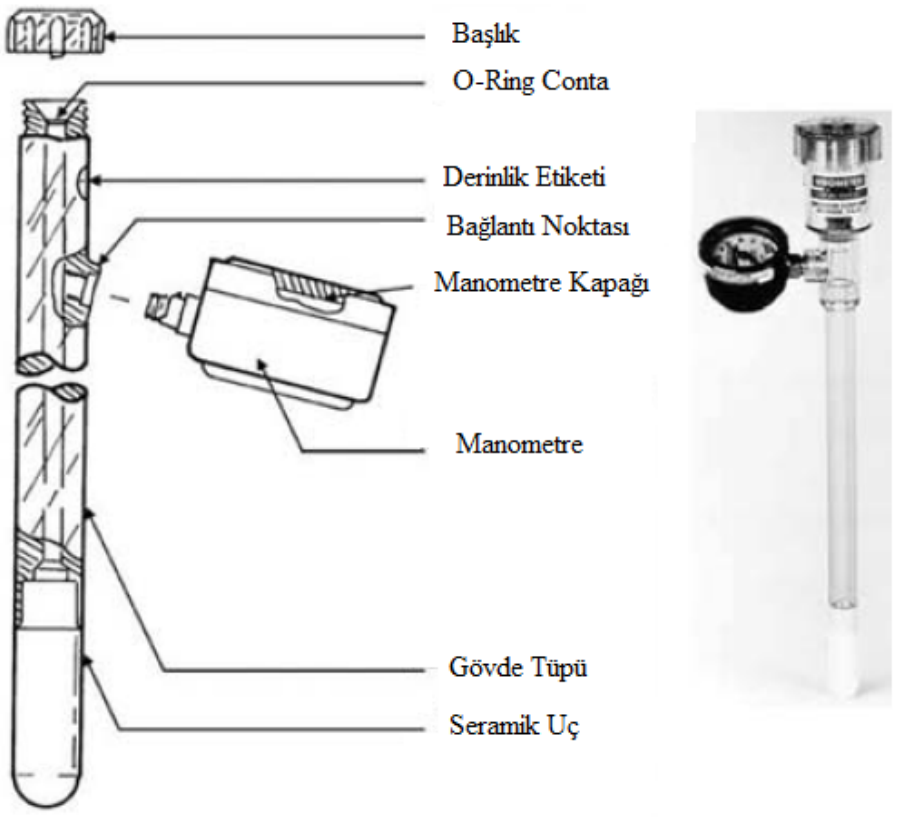

Şekil 8. Tansiyometre [34].

Tüm tansiyometrelerin temel çalışma prensibi; gövdeyi oluşturan su dolu sızdırmaz tüpün, küçük deliklere sahip seramik uç kısmının toprakla temas etmesi ve içerdeki suyun matrik potansiyelinin toprak suyunun matrik potansiyeli ile dengelenmesi mantığına dayanmaktadır [47]. Topraktaki suyun uyguladığı matrik potansiyel, negatif değerle dengelendiği için ölçümler negatif değerlerle okunmaktadır. Tansiyometrelerin arazi kullanımlarından önce ölçüm yapılmak istenen derinliklere kadar çukur açılması gerekmektedir. Tansiyometrenin plastik gövde tüpü bu çukurlara yerleştirilir ve seramik ucun açılan çukura tam olarak oturması ölçülen değerlerin doğruluğu açısından oldukça önemlidir. Topraktaki nem durumuna bağlı olarak; yerleştirilen seramik uçtan toprağa doğru veya topraktan seramik uç aracılığıyla tansiyometreye doğru bir su akışı olur ve matrik potansiyelin dengesi kurulur. Bu dengelenme sonucunda manometreden okunan değer toprak su potansiyelini vermektedir.

Tansiyometrelerin sağlıklı sonuçlar vermesi için toprağın doymamış durumda olması gerekir, dolayısıyla bitki su ihtiyaçlarının tam karşılanmadığı veya su stresi olan durumlarda sulama daha sık kullanılmaktadır [48]. Ölçülen tansiyon değerleri 10 cbar'ın altında kaldığı durumlarda toprağın doygun olduğu anlaşılmaktadır. Tarla kapasitesinde ise ölçülen negatif basınç toprağın çeşidine göre 10-30 cbar arasında değişmektedir (Kumlu topraklarda 10, orta bünyeli topraklarda 20, killi topraklarda 30 cbar). Toprak bünyesine göre tarla kapasitesi değerinden 20 cbar yukarıda ölçülen değerler için (ör: killi topraklar için 50 cbar) nem miktarının ideal seviyede olduğu yorumu yapılabilmektedir. 30-55 cbar aralığını geçen okumalar için ise su stresi yorumu yapılmaktadır ve sulama uygulamalarının başladığı aralık olarak kabul edilmektedir. Tansiyometrelerin 70 cbar ve 85 cbar aralığındaki ölçümler topraktaki elverişli nemin çok büyük miktarının tüketildiği anlamına gelmektedir. Bu değerler tansiyometrelerin üst sınırları olarak ve yöntemin sağlıklı sonuçlar verebildiği son aralık olarak tanımlanmaktadır [8, 45]. Ölçüm aralığının doyma noktası ile 80-85 cbar aralığındaki noktaya kadar olması tansiyometrelerin eksik kalan noktalarından biri olarak kabul edilmektedir. Kullanılan aletlerin avantajları ve dezavantajları Tablo 6.' da verilmiştir. 


\begin{tabular}{|c|c|c|}
\hline & $\begin{array}{l}\text { BŞEÜ Fen Bilimleri Dergisi } \\
8(1), 484-496,2021\end{array}$ & $\begin{array}{r}\text { BSEU Journal of Science } \\
\text { https://doi.org/10.35193/bseufbd.842370 }\end{array}$ \\
\hline 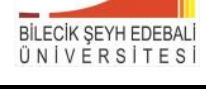 & & 2458-7575 (https://dergipark.org.tr/tr/pub/bseufbd) \\
\hline
\end{tabular}

Tablo 6. Tansiyometrelerin avantajları ve dezavantajları

\begin{tabular}{ll}
\hline \multicolumn{1}{c}{ Avantajlar } & \multicolumn{1}{c}{ Dezavantajlar } \\
\hline Satın alma maliyeti düşüktür. & Çalışma aralığı sınırlıdır (<85 cbar). \\
Kullanımı kolaydır. & Ölçümlerin temsil alanı düşüktür. \\
Tuzluluktan etkilenmez. & Hidrolik iletkenliği düşüktür \\
$\begin{array}{l}\text { Hem kapilar basıncı ölçebilir hem de toprak su içeriği } \\
\text { hakkında bilgi verebilir. }\end{array}$ & $\begin{array}{l}\text { Hidrolik iletkenliğin düşük olduğu durumlar } \\
\text { da okumaların güvenilirliği düşmektedir. }\end{array}$ \\
$\begin{array}{l}\text { Güçtüketimi yoktur. } \\
\text { Çok sayıda ölçüm ihtiyacı olan durumlar için olduk } \\
\text { ça uygundur }\end{array}$ & Kolay zarar görebilmektedir. \\
\hline
\end{tabular}

\section{SONUÇ}

Hemen her sektörde olduğu gibi ziraat alanında da geçmişten günümüze yapılan araştırmalar ve Ar-Ge çalışmalarıyla beraber büyük atılımlar gerçekleşmiştir. Su ve toprak kaynaklarının daha etkili ve verimli şekilde kullanılması adına toprak nem içeriğinin takip edilmesi ve ölçümü için de yeni yöntemler ve cihazlar geliştirilmiştir. Bu gelişme ve farklı yöntemleri daha yakından incelemek amacıyla yapılan literatür çalışmaları sonucunda kullanılan her yöntemin (Gravimetrik yöntem, TDR, FDR, alçı-jips blokları, nötronmetreler ve tansiyometreler) birbirlerine karşı üstünlükleri ve eksiklikleri olduğu görülmüştür. Sonuca daha doğrudan ulaşılması ve kalibrasyon işlemlerine ihtiyaç duyulmaması nedeniyle gravimetrik yöntem diğer yöntemlere göre tercih edilebilmektedir. Bu durum yöntemin geçmişten günümüze en yaygın kullanılan yöntem olmasının başlıca sebeplerindendir. Dolaylı ölçüm yöntemlerinde ölçümün yapıldığı toprağın fiziksel, kimyasal ve içerdiği organik bileşik miktarına bağlı olarak sapmalar görülmektedir. Bu yöntemlerle yapılan ölçümlerde hatayı en aza indirmek için toprak analizlerinin iyi şekilde yapılması ve kalibrasyon işlemlerinin tamamlanması gerekmektedir. Ekonomik ömrü diğer yöntemlere göre nispeten az olarak değerlendirilebilecek alçı-jips bloklarının ve geçmişi uzun yıllara dayanan tansiyometrelerin kullanım aralığının sınırlı olması sebebiyle çeşitli toprak tiplerinde beklentiyi karşılamamış ve araştırmacıları farklı yöntem arayışı içine sokmuştur. Nötronmetre ve TDR cihazların pahalı olması ve nötronmetrelerin güvenli kullanımı için gerçekleştirilmesi gerek lisans işlemleri, bu cihazların çiftçiler tarafından kullanılması daha zor hale getirmektedir. FDR cihazları düşük maliyetleri ile son zamanların popüler yöntemlerinden biri olarak öne çıksa da, ölçümlere ait doğrulukların hem sıcaklıktan hem de tuz ve kil varlığından olumsuz etkilendiği görülmüş̧ür. Sonuç olarak; arazi koşulları, toprak çeşidi, finansal durum, kullanıcının yeterliliği ve mevcut imkânlar gibi farklı parametrelerin değerlendirip elverişli toprak nem tayini yönteminin belirlenmesi ve bu yöntemin prensiplerine bağlı kalınarak uygulama yapılması büyük önem taşımaktadır.

\section{KAYNAKLAR}

[1] Pimentel, D., Houser, J., Preiss, E., White, O., Fang, H., Mesnick, L. \& Alpert, S. (1997). Water resources: agriculture, the environment, and society. BioScience, 47(2), 97-106.

[2] Bates, B., Kundzewicz, Z. \& Wu, S. (2008). Climate change and water. Intergovernmental Panel on Climate Change Secretariat.

[3] Aküzüm, T., Çakmak, B. \& Gökalp, Z. (2010). Türkiye'de Su Kaynakları Yönetiminin Değerlendirilmesi. TABAD Tartm Bilimleri Araştırma Dergisi, 3 (1), 67-74, 2010 ISSN: 1308-3945, E-ISSN: 1308-027X

[4] FAO, (2013). Food and Agricultural Organization (FAO). http://www.fao.org/nr/water/aquastat/main/index.stm (ErişimTarihi: 16.11.2020).

[5] Wang, H., Liu, C. \& Zhang, L. (2002). Water-saving agriculture in China: an overview.

[6] Camp, C.R. (1998). Subsurface drip irrigation: A review. Trans. ASAE, 41(5), 1353-1367.

[7] Sakellariou - Makrantonaki, M. \& Vagenas, I.N. (2006). Mapping Crop Evapotranspiration and Total Crop Water Requirements Estimation in Central Greece. European Water bulletin of EWRA 13/14:3-13. E. W. Publications.

[8] Çetin, Ö. (2003). Toprak-su ilişkileri ve toprak suyu ölçüm yöntemleri. Köy Hizmetleri Genel Müdürlüğü, Eskişehir Araştırma Enstitüsü Müdürlüğü, Genel Yayın, (258), 100.

[9] Smith, R.E. \& Warrick, A.W. (2007). Soil water relationships. In Design and Operation of Farm Irrigation Systems, 2nd Edition (pp. 120-159). American Society of Agricultural and Biological Engineers. 
[10] Voroney, P. \& Sharpe, P. (2019). Soils for horse pasture management. Horse pasture management, 65-78.

[11] Topp, G.C. \& Ferre, P.A. (2002). The soil solution phase. Methods of soil analysis: Part (4), 417-1074.

[12] Topp, G.C. Parkin, G.W., Ferré, T.P., Carter, M.R. \& Gregorich, E.G. (2008). Soil water content. Soil sampling and methods of analysis. 2nd edn.(Eds MR Carter, EG Gregorich) 939-962.

[13] Dirksen, C. (1999). Soil Physics Measurements. Catena Verlag, Reiskirchen, Germany.

[14] Gardner, C.M.K., Robinson, D.A., Blyth, K. \& Cooper, J.D. (2001). Soil water content. In: Soil and Environmental Analysis: Physical Methods (K.A. Smith and C.E. Mullins, eds.), Marcel Dekker, New York, $1-64$.

[15] Gardner, W.H. (1986). Water Content. Chapter 21 in Methods of Soil Analysis, Part I, Physical and Mineralogical Methods. American Society of Agronomy and Soil Science Society of America, Madison, WI, USA.

[16] Anonim, (2017). Cole-Parmer Scientific Experts, Virtual Print Catalog. https://www.coleparmer.com/virtual-catalog/gy44/857 (ErişimTarihi: 03.12.2020)

[17] USDA, (2015). United States Department of Agriculture. Soil Classification, Tools and Data. https://www.nrcs.usda.gov/wps/portal/nrcs/main/soils/survey/tools/ (ErişimTarihi 24.11.2020)

[18] Hanson, B.R. \& Peters, D. (1998). Measuring soil moisture. Irrigation Association Technical Conference Proceedings. November 1-3, 1998, San Diego, California, USA, 103-110

[19] Or, D. \& Wraith, J.M. (1998). Soil physics. Agricultural and Environmental Department of Plants, Soils and Biometerology, Utah State University, Logan, USA, 243

[20] Allen, R.G. (1998). Time-Domain Reflectometry (TDR). Appendix Notes for BIE 5010/6010.

[21] Hoekstra, P. \& Delaney, A. (1974). Dielectric properties of soils at UHF and microwave frequencies. $J$. Geophys. Res., 79, 1699- 1708.

[22] Topp, G.C., Davis, J.L. \& Annan, A.P. (1980). Electromagnetic Determination of Soil Water Content: Measurements İn Coaxial Transmission Lines. Water Resour. Res., 16, 574-582. doi:10.1029/WR016i003p00574

[23] Jackson, T.J. (1990). Laboratory evaluation of a field-portable dielectric/soil moisture probe. IEEE Transactions on Geoscience and Remote Sensing, 28, 241-245.

[24] Muñoz-Carpena, R., Dukes, M.D., Li, Y.C. \& Klassen, W. (2005). Field Comparison of Tensiometer and Irrigation on Tomato. Horttechnology. 15, 584-590.

[25] Smethurst, (2019). Condition monitoring for earthworks. https://www.c-iot.ecs.soton.ac.uk/sites/www.ciot.ecs.soton.ac.uk/files/Joel\%20Smethurst.pdf (ErişimTarihi: 29.11.2020).

[26] Prichard, T.L. (2002). Soil moisture measurement technology. University of California.

[27] Kramer, P.J., \& Boyer, J.S. (1995). Water relations of plants and soil. USA, 84-114

[28] Al-Kaisi, M. (2000). How to evaluate soil moisture in the field. Iowa State University. https://crops.extension.iastate.edu/encyclopedia/how-evaluate-soil-moisture-field (ErişimTarihi: 07.12.2020).

[29] Fiscbach, P. (1971). EC71-752 Scheduling irrigation by electrical resistance blocks. Historical Materials from University of Nebraska- Lincoln Extension.

[30] Werner, H. (1992). Measuring soil moisture for irrigation water management. Cooperative Extension Service, South Dakota State University, US Department of Agriculture.

[31] Martin, E. (2009). Methods of Measuring for Irrigation Scheduling--WHEN. Arizona Cooperative Extension. The University of Arizona, Tucson, Arizona Water Series No. 30.

[32] Robock, A. (2015). Hydrology, floods and droughts: Soil moisture. In Encyclopedia of Atmospheric Sciences: Second Edition, 232-239.

[33] Evett, S.R. \& Steiner, J.L. (1995). Precision of neutron scattering and capacitance type soil water content gauges from field calibration. Soil Science Society of America Journal, 59(4), 961-968.

[34] Muñoz-Carpena, R. (2004). Field devices for monitoring soil water content. EDIS, 8.

[35] Özbek, Ö. \& Kaman, H. (2014). The Definition and Monitoring of Soil Water Content. Türk Tarım ve Doğa Bilimleri Dergisi, 1 (Özel Say1-1), 1067-1071.

[36] Liamsuwan, T., Channuie, J. \& Ratanatongchai, W. (2015). Characterization of neutron calibration fields at the TINT's $50 \mathrm{Ci}$ americium-241/beryllium neutron irradiator. In Journal of Physics: Conference Series, 611(1), 012004.

[37] Grossman, R.B., \& Reinsch, T.G. (2002). Bulk density and linear extensibility. Section 2.1 in Methods of Soil Analysis, Part 4: Physical Methods, 201-228. J. H. Dane, and G. C. Topp, eds. Madison, Wis.: Soil Sci. Soc. America. 
[38] Uytun, A., Pekey, B., \& Kalemci, M. (2013). Toprak nemi ölçümleri. VIII. Ulusal Ölçüm bilim Kongresi, 26-28.

[39] Hauser, V.L. (1984). Neutron meter calibration and error control. Transactions of the ASAE, 27(3), 722-728.

[40] Candoğan, B.N. (2009). Soya Fasulyesinin Su-Verim İlişkileri. Doktora Tezi, Bursa Uludağ Üniversitesi, Fen Bilimleri Enstitüsü. Bursa. 37.

[41] TAEK, (2020). Türkiye Atom Enerjisi Kurumu. 2019 Y1lı Faaliyet Raporu. Strateji Geliştirme Dairesi Başkanlığı, Ankara.

[42] Or, D. (2001). Who invented the tensiometer?. Soil Science Society of America Journal, 65(1), 1-3.

[43] Mualem, Y. (1990). The use of tensiometer readout for irrigation- Success and Failure. 5th International Conference on Irrigation Proceedings, 26-27 March 1990, Tel-Aviv, Israel. 118-130

[44] Richards, L.A. (1949). Methods of measuring soil moisture tension. Soil Sci, 88, 95-112.

[45] Kirkham, M.B. (2014). Principles of soil and plant water relations. Academic Press.

[46] Allen, R.G. (1998). Irrigation Engineering Principles. Course Lecture Notes. Department of Biological and Irrigation Engineering, Utah State University, Logan, Utah, USA. 298

[47] Cassell, D.K., \& Klute, A. (1986). Water potential: tensiometry. methods of soil analysis, Part I. Physical and Mineralogical Methods. Agronomy Monograph No. 9 2nd Edition. American Society of Agronomy -Soil Science Society of America, 677, South Segoe Road, Madison, WI 53711, USA, 23: 563-588

[48] Richards, S.J. (1965). Soil suction measurements with tensiometers. In Methods of Soil Analysis. Part 1. Physical and Mineralogical Properties, Including Statistics of Measurement and Sampling (Black, C.A., Evans, D.D., Ensminger, L.E., White, J.L., and Clark, F.E., Eds.), 153-163. American Society of Agronomy: Madison, Wisconsin. 